\title{
Realising the value of continuous monitoring programmes for biodiversity conservation
}

AUTHORS:

Casparus J. Crous ${ }^{1}$

Francois Roets ${ }^{2}$

AFFILIATIONS:

${ }^{1}$ Forestry and Agricultural

Biotechnology Institute,

University of Pretoria, Pretoria,

South Africa

2Department of Conservation

Ecology and Entomology,

Stellenbosch University,

Stellenbosch, South Africa

\section{CORRESPONDENCE TO: \\ Casparus Crous}

EMAIL:

casper.crous@fabi.up.ac.za

POSTAL ADDRESS:

Forestry and Agricultural

Biotechnology Institute, University of Pretoria, Private Bag X20, Hatfield 0028, South Africa

\section{KEYWORDS:}

commodity production; eco-agriculture; Gyronotus glabrosus; infrastructure; South Africa

\section{HOW TO CITE:}

Crous CJ, Roets F. Realising the value of continuous monitoring programmes for biodiversity conservation. S Afr J Sci. 2014;110(11/12), Art. \# a0083, 5 pages. http://dx.doi. org/10.1590/sajs.2014/a0083

(C) 2014. The Author(s). Published under a Creative Commons Attribution Licence.
There is an increased need for support for continuous biodiversity monitoring programmes in commodity production landscapes; the pressure for such supports arises from a variety of sources. We highlight our rediscovery of a presumed extinct dung beetle species, last recorded in 1975, to accentuate the value of local-scale ecological monitoring approaches for modern conservation planning practices in South Africa. We believe this perspective could help articulate further growth in support for such infrastructure.

\section{Advances in biodiversity conservation in production landscapes}

In recent times, there has been a global increase in awareness of the important function of biodiversity conservation in commodity production landscapes. ${ }^{1}$ We now better understand that many aspects of biodiversity, such as insects responsible for pollination, or certain plants that purify water in wetlands, are extremely valuable in production landscapes. ${ }^{2}$ To allow for the sustainable use of these ecosystem goods and services, many environmental schemes were initiated worldwide, which encourage and provide financial help for land-users to implement 'ecoagricultural' systems. ${ }^{3}$ A well-documented example is the European Agri-Environment Schemes. When these schemes are implemented appropriately (with the right knowledge base; involving collaboration between scientists, policymakers and practitioners; and effective on-site supervision), this modern production paradigm can have great reward for both the land-user, and local species diversity. ${ }^{4,5}$ However, across the global commodity production landscape, the incentives for environmentally conscious initiatives, and their subsequent implementation and monitoring, do vary considerably. ${ }^{6}$ In some instances such initiatives are legislated, while in others, environmentally conscious commodity production is guided by trade standards (voluntary 'user-pays' participation). These trade standards are usually ushered by modern consumer pressure (such as a need for more ecologically sensitive production), and essentially bridge the lack of local environmental legislation in a country (e.g. international commodity production regulatory bodies such as Global Good Agricultural Practice and the Forestry Stewardship Council (FSC)). For some land-users, producing goods in an environmentally sensitive way can also be motivated by a desire to be naturally sensible (e.g. for aesthetic reasons or because of a personal conviction).

In the timber industry specifically, the FSC provides a global certification framework whereby adhering to certain production standards, and thus being certified under this trademark, not only increases your company's status as an environmentally responsible land-user, but also offers socio-economic advantages (such as access to certain markets). For the past few years, as ecologists who consult independently of agricultural regulatory bodies, we have been involved in the environmental monitoring process for a FSC certified plantation forestry company in South Africa. Our involvement came about as the FSC auditors requested corrective actions to address the lack of knowledge (or acknowledgment) of rare, threatened or endangered species within the production landscape. During this time, we have learnt that requirements for continuous biodiversity monitoring as part of trade standards certification schemes, such as FSC, may act as a barrier to participation for companies or individuals who are unwilling or unable to resource such monitoring indefinitely. This has raised the issue of the role of continuous biodiversity monitoring and its potential in local (on-site) environmental sustainability initiatives.

\section{Continuous monitoring programmes for biodiversity conservation}

The value of implementing the principles of monitoring in conservation programmes, for example with the use of indicator species, was identified early on as contributing to more ecologically sound on-site managerial decisions. ${ }^{7}$ In most managed semi-natural open spaces, the continuous monitoring of biodiversity is probably the most crucial aspect in verifying and ultimately determining conservation success. ${ }^{8}$ In fact, continuous monitoring can be one of the most critical strategies to help reduce uncertainty (e.g. from imperfect biological or ecological knowledge of species) when practical managerial recommendations have to be made for the long-term success of managed populations. ${ }^{9-11}$ As highlighted by Magurran et al. ${ }^{9}$, it is imperative for an environmentally conscious land-user who is serious about contributing to the conservation of a landscape to (1) initiate biodiversity inventories, using a standardised approach, on all the different habitats or biotopes on their properties and (2) commit to implementing follow-up monitoring of these sites (for long-term data sets). This approach would eventually provide useful scientific insights into observed increases or decreases in specified fauna and flora, especially regarding which environmental variables could have determined these patterns (such as changes in agricultural management practices in the matrix, e.g. pesticide usage), and how to subsequently adapt the conservation management in local habitats or biotopes. ${ }^{12,13}$ This process will also increase the chance of discovering those rare, threatened or endangered species (or even just the abundant but highly localised ones).

\section{The rationale for this perspective}

There is a vast literature showing the benefits to biodiversity for European countries when implementing agricultural environmental programmes, such as European Agri-Environment Schemes, at local scales (i.e. the scale of management intervention such as fields, farms or catchments). ${ }^{14,15}$ However, we have also learnt from European Agri-Environment Schemes that at the scale of policy intervention (national measures of diversity or species abundance), there is little evidence of success in showing national biodiversity benefits. ${ }^{16} \mathrm{~A}$ similar trend was observed regarding invasive alien plants and the overall impact of policies on curbing global biodiversity declines. ${ }^{17}$ These trends illustrate the spatially varied application of local-scale conservation management and policy interventions. Fundamentally, the more evidence we can obtain that shows positive impacts of local-scale conservation initiatives on biodiversity, the more we should be able to influence national policy objectives to 
further support such initiatives, thereby reducing the implementation gap. Indeed, Donald et al. ${ }^{18}$ accentuated the enormous importance of available empirical evidence to help formulate bird conservation policies in Europe, which would support the proof of feasibility and efficacy of current conservation recommendations.

South Africa is a major commodity producing country, and needs to stay competitive in a more environmentally conscious market. Therefore, given the global idiosyncrasies in biodiversity conservation initiatives in agri-landscapes worldwide, we provide here some compelling evidence as to the value of continuous monitoring programmes in privately organised commodity production landscapes in South Africa. We aim to convey a plight for an increased awareness and appreciation of such programmes in helping environmentally conscious parties to obtain critical evidence-based (more scientifically accurate) conservation planning, as well as to help articulate support for such infrastructure in commodity production landscapes in South Africa.

\section{Hidden on the forest floor - A continuous monitoring success story}

Mountainous areas in South Africa are considered centres of high endemism, in which conservation research is seen as a priority. ${ }^{19}$ Since 2012, monitoring sites have been set up on fragments of threatened Afro-montane (African mountain) forest patches in a plantation forestry matrix in the Tzaneen area (Limpopo Province, South Africa). These forest patches are part of the Northern Mistbelt Forests vegetation type. We specifically chose the Northern Mistbelt Forests in this area, as it is an extensive agricultural area (major producers of fruit and timber in South Africa), with very few of these forest patches continuously monitored with regard to such encroaching threats. As a result of continuous follow-ups on these sites, in late 2013, we rediscovered a dung beetle that had been presumed to be extinct.

We have now confirmed the presence of Gyronotus glabrosus (Scarabaeidae) on one of the higher elevation forest sites on the estate. All species in this genus seem to be very sensitive to habitat disturbance and their presence can indicate good habitat quality. ${ }^{20} \mathrm{G}$. glabrosus is a flightless, medium-sized and slightly flattened black beetle (about $12 \mathrm{~mm}$ long) which was first described in 1987 (Figure 1). ${ }^{21}$ From the literature, this species was last recorded in 1975 from the Nerina Nature Reserve in Magoebaskloof (adjacent to the town of Tzaneen). ${ }^{21}$ This area was, however, cleared of natural vegetation for extensive commercial Eucalyptus forestry. During 2000, extensive surveys in the area failed to record this species and it was therefore presumed to be either critically endangered or extinct. ${ }^{22}$ It is currently only known from seven museum specimens. The collection of six specimens (three mating pairs) during this survey on the margins of this high elevation forest site therefore represents not only the rediscovery of this species, but also currently its only known locality.

The presence of this very sensitive species in the area is therefore indicative of good current habitat integrity with little disturbance. From this, at least, we can now argue that all efforts should be made to maintain the future integrity of this habitat in order to ensure the long-term survival of this very rare species. In fact, the ecological and economic importance of smaller animals is often ignored, but when ecological imbalances result from their exclusion, their significance cannot go unnoticed. For example, in Australia, Uruguay and the USA, the importance of dung beetles in organic recycling and pest management became very apparent after large losses in cattle industries as a result of outbreaks caused by dung-breeding nuisance and bloodsucking pests. ${ }^{22}$ Many dung beetles are specialised to particular soils, vegetation food types etc., which also makes them very good indicators of ecosystem health. The loss of specialised species and an increase in non-specialists, for example, is a good indication that ecosystem integrity is compromised. Furthermore, southern African Afro-montane forests, one of the most endangered vegetation types in Africa, house the largest number of endangered dung beetle species. ${ }^{22,23}$ How many more rare or localised species could be found in these remaining forest patches within major production landscapes?

\section{The way forward}

\section{Creating awareness}

The popular philosophical question, 'If a tree falls in a forest, and no one is there to hear it, does it make a sound?', challenges our perception of reality in absence of observation. We can also ask: If a dung beetle strolls on the forest floor, and no one is there to observe it, does it exist? The plain answer is that we need to prove its existence, and this is where we most often fall short, as without evidence, it becomes impossible, or at best circumstantial, to infer life. It can be argued that, in general, only when one allocates a name and value to an entity, one would be more inclined to accept responsibility for that entity, and can therefore better perceive a loss (and act upon it). Thus, in a production landscape context, without a biodiversity monitoring programme, many land-users would not be aware of the value of their natural capital, and would therefore not perceive any problem, or expect any future ecosystem failure. When we take into account the enormous lack of taxonomic knowledge of species in existence today, and their yet unknown dispersion patterns, the reality of starting monitoring programmes should become a natural response for the environmentally conscious parties which underwrite sustainable commodity production landscapes. Essentially, we have created these ecosystem fragments without knowing what we have left in our wake (the collateral damage). It would be naïve to accept that remnant natural (or semi-natural) patches are by default inhospitable to all living things, no matter what the size of these fragments, or their appearance (perceived health). With so many fragments (natural and semi-natural) left on private properties (mostly situated within a matrix of commodity production activities) with no properly structured continuous monitoring initiatives, a natural step would be to stress the importance of such programmes in these often overlooked areas. In doing so, we should have a better chance of finding new or presumably lost species and detect changes in ecosystem functioning. We can therefore extend our philosophical question posited above to a more applied tier: Will these unknown species continue to be? This we can only infer when we know what exists, where it exists, what it is doing there (niches), and how it responds to change. If we do not provide clear evidence of this nature, we would inherently fail in making more land-users aware of the value of remnant biotopes or habitats in commodity production landscapes, and therefore fail in gaining the relevant local policy support. ${ }^{18}$ We believe that philosophical questions of this nature are highly relevant to most agricultural landscapes today, and can therefore be used to advocate awareness of biodiversity beyond the known.

\section{The necessary infrastructure}

South Africa is seen as a developing country. It is therefore positive to see that more and more people, academic or not, are becoming aware of the benefits of biodiversity conservation for humanity. For example, most universities in South Africa today provide degrees in conservation biology, or some course work in environmental management, and from our personal experience, we have seen these classes growing in student numbers in the past decade. As environmental education within the infrastructure improves, there should be an increase in knowledge that can be applied to environmental problems in agri-landscapes in South Africa. Of course, one can only apply knowledge if we are aware of a specific problem. In particular, we would want to see these environmentally interested parties being made more aware of how their knowledge can be applied to biodiversity inventorying, and, most importantly, continuous monitoring of these inventories. With the advent of environmental regulations (FSC, for example), and their (theoretical) future permanence in production landscapes, more opportunities for ecology professionals will eventually arise. Hill and Arnold ${ }^{24}$ highlighted the enormous growth in opportunities for entrepreneurial endeavours in ecological consultation - information that these budding professionals should be made cognisant of.

Outside of conservation professionals, many other stakeholders could help with continuous monitoring protocols. Magurran et al. ${ }^{9}$ reviewed the current trend in which more and more people are becoming interested in environmental matters, which creates a valuable opportunity for 


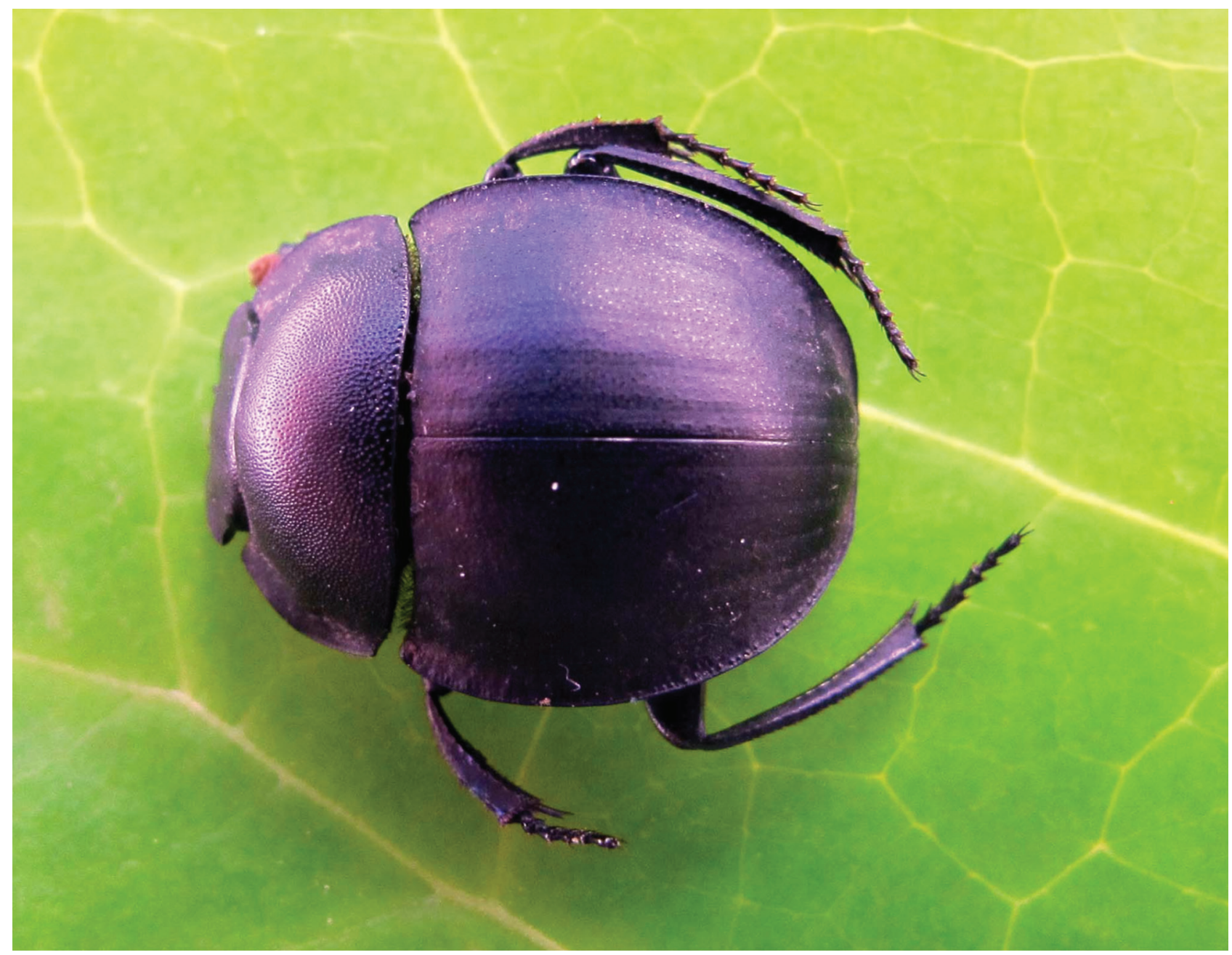

Figure 1: One of the rediscovered Gyronotus glabrosus individuals (Scarabaeidae). This genus belongs to the Canthonini tribe, which is considered to be of substantial biodiversity and conservation value. ${ }^{20}$

citizen science in aiding the continuous monitoring ideal. For example, a farmer who has always been interested in the natural aspects of their farm, often possesses great knowledge of what species occur or have occurred on the property. This local knowledge would not only add great value to past recollections, but would also help to improve the chances of observing more species. Moreover, we can now better determine the factors that influence ecological processes at a local scale.

From an economic perspective, it is known that we live in a world of trade-offs. Given the high monetary value of ecological services, we cannot circumvent the role that business strategy would have in providing such infrastructure. ${ }^{24}$ Someone has to pay for professionals to render continuous assessments, and land-users may want something in return (something of monetary value to them). We know there are many idiosyncrasies in incentives for performing continuous monitoring - for example, if a land-user is liable by law, certification, or through personal conviction. Although we provide no direct solution for the chronic funding debate here, we can re-appreciate the value of an evidence-based approach to help argue for support for continuous monitoring. We can relate species evidence as biological capital, to argue for conservation capital from companies for such initiatives. ${ }^{25}$ Lindenmayer et al. ${ }^{13}$ also argued that improved biodiversity monitoring is often constrained by poorly articulated objectives. In this light, seven critical topics are apparent to help stimulate discussions on the value of continuous monitoring programmes in South African production landscapes:

1. Continuous monitoring and subsequent maintenance of local open spaces will eventually help us create fairly stable indigenous refuges that are important for the welfare of a variety of indigenous biota, especially the rare and endemic ones.

2. Long-term on-site (local) observations on the different biotopes in a given landscape are the only reliable way to determine changes in community dispersion patterns. Any biotope could provide the unique niche resources for diverse biota, and detecting changes to biotic communities (for which we now have baseline data), would enable conservation biologists to more accurately predict which variables (natural or anthropogenic) significantly influence observed changes.

3. We can obtain far more focused or goal-orientated conservation planning. For example, an increase in $x$ disturbance may lead to a decrease in $y$ species.

4. For current and proposed production landscapes, implementing biodiversity monitoring programmes is highly relevant considering South Africa ratified the Convention on Biological Diversity's 2020 Aichi Biodiversity Targets. The vision of these biodiversity targets is essentially to 'live in harmony with nature'. When a country agrees to strive towards these targets, they agree to make sure that the biodiversity of their country is valued, conserved, restored where needed, and ultimately sustainably used for the well-being of all citizens, and, of course, the planet as a whole (see www.cbd.int for more information).

5. Locally organised continuous monitoring programmes, given the right communication structures, would complement already 
established national or regional monitoring initiatives, such as the South African Environmental Observation Network. ${ }^{26}$

6. There is an established marketing incentive for adhering to voluntary responsible land-user programmes, such as access to niche markets (for example, the Biodiversity and Wine Initiative in South Africa). The land-owner gets information of unexplored territories on their property, which may increase eco-tourism, cultural or aesthetic value.

7. There is a feel-good factor involved. The idea that one adds to life and living, and not only resource extraction. That a new or 'lost' species was discovered on a property, at least for some people, could be highly thought provoking (hinting again at awareness). Given the right communication channels, interesting stories from the field can inspire and awe the general public, especially educational institutions such as schools.

With regard to specifically asking for funding for such continuously running tasks, we feel that some early recognised insights of Lindenmayer ${ }^{8}$ are still highly relevant today: to be innovative and contemporary - relating to a modern, technologically and environmentally conscious people (how does this aid in the health of families and through which interesting media can this message be conveyed); to reveal the strong scientific base behind long-term data gathering; be experts - or state their involvement; and, finally, be explicit in how you will ensure these data are implemented (discuss the feasibility of conservation management recommendations for the land managers ${ }^{10}$ ). Essentially, it is clear that, at present, there is expert consensus on the high value and logic of continuous monitoring programmes in modern conservation practices, worldwide. It is even clearer that the necessary infrastructure for such programmes needs redress. ${ }^{13}$

\section{To conclude}

In this modern ecoagricultural context, many land-users accept some responsibility for severely transforming the earth's surface. To perhaps paraphrase a land-user for whom we consulted:

\begin{abstract}
I did not know I should plan for conservation; my father never taught me this value as being essential to farming practice, but I now recognise its worth for the sustainability of my business, and the local landscape from which it derives.
\end{abstract}

This is just one anecdote, but, essentially, environmental consciousness is increasing, numbers of skilled professionals are correspondingly increasing, and we are slowly becoming more aware of the increased scope for entrepreneurial growth in applied ecological science. The basis of promoting continuous monitoring programmes is a derivative of these factors, and would unquestionably complement current national or regional observation strategies, for which continually monitoring so many sites is an enormous task. Moreover, increasing continuous monitoring infrastructure would demonstrate a deep realisation of the Convention on Biological Diversity's 2020 Aichi Targets on all facets of commodity production (large-scale, small-scale and subsistence farmers). Unfortunately, the mitigating efforts to rectify bad management practices are not consistently distributed across producing countries. For South Africa, the rediscovery of this critically endangered dung beetle species within a major commodity production landscape, specifically on areas previously never subjected to biodiversity monitoring, should serve as a wake-up call for improved continuous monitoring infrastructure, across all hierarchies (legislation, certification, private companies and citizen science). Increased awareness and realisation of the value of applied ecological approaches to farmland conservation, would rightly position a country, especially developing countries like in southern Africa, to advance in a time when biodiversity conservation forms an integral part of the commodity production landscape.

\section{Acknowledgements}

We wish to thank Jeremy Wilson for providing helpful comments on a previous draft of this manuscript.

\section{References}

1. Fischer J, Lindenmayer DB, Manning AD. Biodiversity, ecosystem function, and resilience: Ten guiding principles for commodity production landscapes. Front Ecol Environ. 2006;4:80-86. http://dx.doi.org/10.1890/15409295(2006)004[0080:BEFART]2.0.C0;2

2. Power AG. Ecosystem services and agriculture: Tradeoffs and synergies. Phil Trans R Soc B. 2010;365:2959-2971. http://dx.doi.org/10.1098/rstb. 2010.0143

3. Scherr SJ, McNeely JA. Biodiversity conservation and agricultural sustainability: Towards a new paradigm of 'ecoagriculture' landscapes. Phil Trans R Soc B. 2008;363:477-494. http://dx.doi.org/10.1098/rstb. 2007.2165

4. Whittingham MJ. The future of agri-environment schemes: Biodiversity gains and ecosystem service delivery? J Appl Ecol. 2011;48:509-513. http:// dx.doi.org/10.1111/j.1365-2664.2011.01987.x

5. McKenzie AJ, Emery SB, Franks JR, Whittingham MJ. Landscape-scale conservation: Collaborative agri-environment schemes could benefit both biodiversity and ecosystem services, but will farmers be willing to participate? J Appl Ecol. 2013;50:1274-1280. http://dx.doi.org/10.1111/1365-2664.12122

6. Pascual U, Perrings $\mathrm{C}$. Developing incentives and economic mechanisms for in-situ biodiversity conservation in agricultural landscapes. Agric Ecosyst Environ. 2007;121:256-268. http://dx.doi.org/10.1016/j.agee.2006.12.025

7. Noss RF. Indicators for monitoring biodiversity: A hierarchical approach. ConservBiol. 1990;4:355-364. http://dx.doi.org/10.1111/j.1523-1739.1990. tb00309.x

8. Lindenmayer DB. Future directions for biodiversity conservation in managed forests: Indicator species, impact studies and monitoring programmes. Forest Ecol Manag. 1999;115:277-287. http://dx.doi.org/10.1016/S03781127(98)00406-X

9. Magurran AE, Baillie SR, Buckland ST, Dick JMcP, Elston DA, Scott EM, et al. Long-term datasets in biodiversity research and monitoring: Assessing change in ecological communities through time. Trends Ecol Evol. 2010;25:574-582. http://dx.doi.org/10.1016/j.tree.2010.06.016

10. Sergeant CJ, Moynahan BJ, Johnson WF. Practical advice for implementing long-term ecosystem monitoring. J Appl Ecol. 2012;49:969-973. http:// dx.doi.org/10.1111/j.1365-2664.2012.02149.x

11. Yokomizo H, Coutts SR, Possingham HP. Decision science for effective management of populations subject to stochasticity and imperfect knowledge. Popul Ecol. 2014;56:41-53. http://dx. doi.org/10.1007/s10144-013-0421-2

12. Van Wilgen BW, Govender N, Forsythe GG, Kraaij T. Towards adaptive fire management for biodiversity conservation: Experience in South African National Parks. Koedoe. 2011;53(2), Art. \#982, 9 pages. http://dx.doi. org/10.4102/koedoe.v53i2.982

13. Lindenmayer DB, Gibbons P, Bourke M, Burgman M, Dickman CR, Ferrier, $\mathrm{S}$, et al. Improving biodiversity monitoring. Austral Ecol. 2012;37:285-294. http://dx.doi.org/10.1111/j.1442-9993.2011.02314.x

14. Kleijn D, Baquero RA, Clough Y, Díaz M, De Esteban J, Fernández F, et al. Mixed biodiversity benefits of agri-environment schemes in five European countries. Ecol Lett. 2006;9:243-254. http://dx.doi.org/10.1111/j.14610248.2005.00869.x

15. Albrecht M, Duelli P, Müller C, Kleijn D, Schmid B. The Swiss agri-environment scheme enhances pollinator diversity and plant reproductive success in nearby intensively managed farmland. J Appl Ecol. 2007;44:813-822. http:// dx.doi.org/10.1111/j.1365-2664.2007.01306.x

16. Kleijn D, Rundlöf M, Scheper J, Smith HG, Tscharntke T. Does conservation on farmland contribute to halting the biodiversity decline? Trends Ecol Evol. 2011;26:474-481. http://dx.doi.org/10.1016/j.tree.2011.05.009

17. McGeoch MA, Butchart SHM, Spear D, Marais E, Kleynhans EJ, Symes A, et al. Global indicators of biological invasion: Species numbers, biodiversity impact and policy reponses. Divers Distrib. 2010;16:95-108. http://dx.doi. org/10.1111/j.1472-4642.2009.00633.x 
18. Donald PF, Sanderson FJ, Burfield IJ, Bierman SM, Gregory RD, Waliczky Z. International conservation policy delivers benefits for birds in Europe. Science. 2007;317:810-813. http://dx.doi.org/10.1126/science.1146002

19. Clark VR, Barker NP, Mucina L. The great escarpment of southern Africa: A new frontier for biodiversity exploration. Biodivers Conserv. 2011;20:25432561. http://dx.doi.org/10.1007/s10531-011-0103-3

20. Moretto P, Perissinotto R. Description and ecology of two new species of Gyronotus van Lansberge, 1874 (Coleoptera, Scarabaeidae) from southern Africa. ZooKeys. 2013;344:73-82.

21. Scholtz $\mathrm{CH}$, Howden HF. A revision of the African Canthonina (Coleoptera: Scarabaeidae: Scarabaeinae). J Entomol Soc S Afr. 1987;50:75-119.

22. Davis ALV, Frolov AV, Scholtz CH. The African dung beetle genera. Pretoria: Protea Book House; 2008.
23. Roets F, Oberlander KC. Silvaphilus: A new relict forest-endemic Canthonini dung beetle genus from the Western Cape Province of South Africa (Coleoptera: Scarabaeidae: Scarabaeinae). Afr Entomol. 2010;18:369-373. http://dx.doi.org/10.4001/003.018.0213

24. Hill D, Arnold R. Building the evidence base for ecological impact assessment and mitigation. J Appl Ecol. 2012;49:6-9. http://dx.doi.org/10.1111/j.13652664.2011.02095.x

25. Harrington DR, Khanna M, Zilberman D. Conservation capital and sustainable economic growth. Oxf Econ Pap. 2005;57:336-359. http://dx.doi.org/ 10.1093/oep/gpi010

26. Van Jaarsveld AS, Pauw JC, Mundree S, Mecenero S, Coetzee BWT, Alard GF. South African Environmental Observation Network: Vision, design and status. S Afr J Sci. 2007;103:289-294. 